\title{
MOLECULAR DYNAMICS SIMULATIONS OF LEAD AND LITHIUM IN LIQUID PHASE.
}

\author{
A. Fraile, S.Cuesta-López ${ }^{*}$, J.M. Perlado \\ Instituto de Fusión Nuclear, ETSI Industriales, Universidad Politécnica de Madrid. \\ José Gutierrez Abascal, 2. 28006, Madrid. Spain. ${ }^{*}$ Contact: santiago.cuesta.lopez@upm.es
}

$\mathrm{Pb} 17 \mathrm{Li}$ is today a reference breeder material in diverse fusion $R \& D$ programs worldwide. Extracting dynamic and structural properties of liquid $\mathrm{LiPb}$ mixtures via molecular dynamics simulations, represent a crucial step for multiscale modeling efforts in order to understand the suitability of this compound for future Nuclear Fusion technologies. At present a $\mathrm{Li}-\mathrm{Pb}$ cross potential is not available in the literature. Here we present our first results on the validation of two semi-empirical potentials for $\mathrm{Li}$ and $\mathrm{Pb}$ in liquid phase. Our results represent the establishment of a solid base as a previous but crucial step to implement a LiPb cross potential. Structural and thermodynamical analyses confirm that the implemented potentials for $\mathrm{Li}$ and $\mathrm{Pb}$ are realistic to simulate both elements in the liquid phase.

\section{INTRODUCTION}

One of the main issues in current Nuclear Fusion programs (particularly magnetic confinement fusion) is the problem of liquid metals breeder blanket behavior. The structural material, constituting the blanket should meet high-performance requirements because of extreme operating conditions. The experimental data available are still scarce and sometimes the experimental uncertainty is important ${ }^{1}$. Therefore the knowledge of eutectic properties like optimal composition, physical and thermodynamical behavior or diffusion coefficients of tritium, are extremely necessary for current designs. In particular, the knowledge of the function linking the tritium concentration dissolved in liquid materials with the tritium partial pressure at a liquid/gas interface in equilibrium, $\mathrm{C}_{\mathrm{T}}=\mathrm{f}\left(\mathrm{P}_{\mathrm{T}}\right)$, is of basic importance because it directly impacts all functional properties of a blanket determining: tritium inventory, tritium permeation rate and tritium extraction efficiency. Nowadays, understanding the structure and behavior of this compound is therefore a real goal in fusion engineering and materials science.

The molecular dynamics (MD) study of liquid lithium and lead reported in this manuscript, is the first work in the literature testing the validity and the implementation of EAM potentials to model metals like $\mathrm{Pb}$ or $\mathrm{Li}$ in liquid phase. In addition, it represents the first step in order to develop a LiPb cross potential for classical MD simulations able to understand the physics underlying the properties of the eutectic mixture in working conditions of interest for Nuclear Fusion technology.

\section{INTEREST OF Pb AND Li IN THE CONTEXT OF FUSION ENERGY}

In different blanket concepts $\mathrm{Li} 17 \mathrm{~Pb}$ is foreseen as tritium breeder and neutron multiplier: in different blanket concepts, Helium Coolant Lithium-Lead (HCLL), Water Coolant Lithium Lead (WCLL), Dual Coolant (DCLL) etc being HCLL concept selected as EU Test Blanket Module (TBM) to be tested in ITER ${ }^{2}$. Much experimental and theoretical work has been done in the past years, covering many aspects of compatibility between PbLi and its environment. Particularly, significant results have been achieved in the field of corrosion of steels, refractory metals and ceramic materials MHD effects etc. However despite of so many efforts PbLi-hydrogen isotope interaction and Tritium extraction technology are still critical issues.

Next table (Table I) compare some physical properties of lithium-lead eutectic alloy, namely $\mathrm{Li}_{17} \mathrm{~Pb}$ or $\mathrm{Li}_{17} \mathrm{~Pb}_{83}$, (the exact title his not been yet determined) with other possible breeding materials as pure lithium, fluorlithium salts (Flibe) and other eutectics like $\mathrm{Li}_{20} \mathrm{Sn}_{80}$. Current studies point that $\mathrm{LiPb}$ has fairly good breeding properties and middle chemical activity. For instance, a clear advantage will be that tritium release would be just $\mathrm{T}_{2}$ and/or HT instead of TF for example when using Flibe

Importantly, only the order of the diffusivity is known, and dispersion in solubility results depending on the technique makes the database inadequate for design purposes. Some reason seems to be the strong dependence of tritium solubility with lithium concentration. This is one of the main reasons that make so important the exact determination of eutectic point in the LiPb system. (See figure 2). 


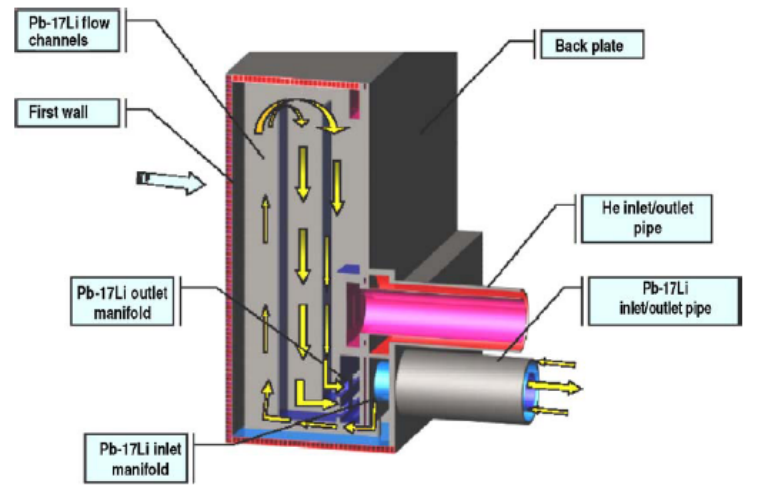

Fig. 1. Dual Coolant Lead-Lithium (DCLL) concept. Configuration for the Reference Tokamak reactor design. Taken from the work of Wong et al ${ }^{3}$. LiPb works as coolant as well as a tritium breeder, i.e. tritium production $(\mathrm{Li}+\mathrm{n} \rightarrow \mathrm{He}+\mathrm{T})$.

TABLE I. Physical properties of eutectic LiPb compared with other possible breeding materials.

\begin{tabular}{|c|c|c|c|c|}
\hline $\begin{array}{l}\text { Liquid } \\
\text { Breeder }\end{array}$ & $\mathrm{Li}$ & $\mathrm{Li}_{17} \mathrm{~Pb}_{83}$ & Flibe & $\mathrm{Li}_{20} \mathrm{~Pb}_{80}$ \\
\hline $\begin{array}{c}\text { Melting } \\
\text { Point }\left({ }^{\circ} \mathrm{C}\right)\end{array}$ & 180 & 235 & 459 & 320 \\
\hline $\begin{array}{c}\text { Density } \\
\left(\mathrm{g} / \mathrm{cm}^{3}\right) 873 \mathrm{~K}\end{array}$ & 0.48 & 8.98 & 2.0 & 6.0 \\
\hline $\begin{array}{c}\text { Li Density } \\
\left(\mathrm{g} / \mathrm{cm}^{3}\right) 873 \mathrm{~K}\end{array}$ & 0.48 & 0.061 & 0.28 & 0.09 \\
\hline $\begin{array}{l}\text { Breeding } \\
\text { property }\end{array}$ & Good & Fairly good & $\begin{array}{l}\text { Neutron } \\
\text { multipler } \\
\text { required }\end{array}$ & $\begin{array}{l}\text { Neutron } \\
\text { multipler } \\
\text { required }\end{array}$ \\
\hline $\begin{array}{l}\text { Chemical } \\
\text { stability }\end{array}$ & Active & Middle & $\begin{array}{l}\text { Almost } \\
\text { stable }\end{array}$ & $\begin{array}{l}\text { Almost } \\
\text { stable }\end{array}$ \\
\hline Corrosion & Severe & Middle & $\begin{array}{l}\text { HF exist } \\
\text { severe }\end{array}$ & $?$ \\
\hline $\begin{array}{c}\text { Tritium } \\
\text { release form }\end{array}$ & $\mathrm{HT}, \mathrm{T}_{2}$ & $\mathrm{HT}, \mathrm{T}_{2}$ & $\mathrm{HT}, \mathrm{T}_{2} \mathrm{TF}$ & $\mathrm{HT}, \mathrm{T}_{2}$ \\
\hline $\begin{array}{c}\text { Tritium solubility } \\
\text { (atom fracPa }^{-0.5} \\
\mathrm{~T}=873 \mathrm{~K} \text { ) }\end{array}$ & $\begin{array}{l}\text { Very high } \\
7.49 \times 10^{-3}\end{array}$ & $\begin{array}{c}\text { Very low } \\
1.93 \times 10^{-8}\end{array}$ & $\begin{array}{c}\text { Very low } \\
\mathrm{HT} / \mathrm{T}_{2} \\
1.77 \times 10^{-11} \\
\mathrm{TF} \\
1.77 \times 10^{-11} \\
\end{array}$ & $\begin{array}{l}\text { Middle } \\
2 \times 10^{-7}- \\
1 \times 10^{-5}\end{array}$ \\
\hline $\begin{array}{l}\text { Tritium } \\
\text { diffusivity order } \\
\left(\mathrm{m}^{2} / \mathrm{s}\right)(873 \mathrm{~K})\end{array}$ & $\begin{array}{l}\text { Relatively } \\
\text { high } \\
10^{-9}\end{array}$ & $\begin{array}{l}\text { Relatively } \\
\text { high } \\
10^{-9}\end{array}$ & $\begin{array}{l}\text { Relatively } \\
\text { high } \\
10^{-9}\end{array}$ & $\begin{array}{l}\text { Relatively } \\
\text { high } \\
10^{-9}\end{array}$ \\
\hline $\begin{array}{c}\text { Thermal } \\
\text { conductivity }\end{array}$ & \multicolumn{4}{|c|}{$\mathrm{Li}>\mathrm{Li}_{20} \mathrm{Sn}_{80}>\mathbf{L i}_{17} \mathbf{P b}_{83}>$ Flibe } \\
\hline $\begin{array}{l}\text { Dynamic } \\
\text { viscosity }\end{array}$ & \multicolumn{4}{|c|}{ Flibe $>\mathrm{Li}_{20} \mathrm{Sn}_{80} \sim \mathbf{L i}_{17} \mathbf{P b}_{\mathbf{8 3}}>\mathrm{Li}$} \\
\hline
\end{tabular}

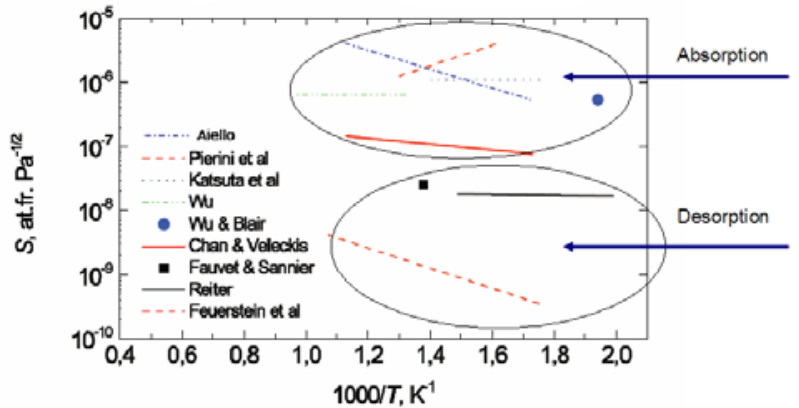

Fig. 2. Solubility database is inadequate for design. Scatter reflects experimental approaches and measurement techniques applied. Knowledge of dynamic transport properties (diffusion, mass transfer, interface processes) is much more limited. (extracted from ref 4).

\section{METHODOLOGY. MOLECULAR DYNAMICS SIMULATIONS.}

Since we are interested in both dynamical and structural properties of liquid metals, Molecular Dynamics by means of Embedded Atom Method (EAM) potentials has been the description methodology of our choice.

For $f c c / b c c$ and other close-packed metals, the embedded atom method (EAM) is a common representation for the energy functional in $\mathrm{MD}$ simulations. It overcomes the volume dependent limitation of pair-potentials by adding a term for the energy to embed an atom in the background electron density of its neighbors. The EAM has proven particularly good at modeling bulk and defect properties (energy, structure) of metals and metal alloys. For example, many MD and Monte Carlo simulations of surfaces and grain boundaries have been performed using the EAM to model such phenomena as crack growth ${ }^{5}$, surface reconstruction ${ }^{6}$ and grain boundary structure ${ }^{7}$. The basic foundations of this class of potentials and the way in which interactions are computed, ensure optimal integration and optimal parallel computation, what it is expected to be extensive to liquid metals and their alloys.

\section{III.A EAM potential for $\mathbf{P b}$}

We have used the EAM potential proposed by Zhou et $\mathrm{al}^{8}$. This potential is already implemented in LAMMPS package 9 , and adjustable parameters involved in the description of pair potential interaction, embedding and density functions were respectively tuned following Zhou details ${ }^{8}$. 


\section{III.A EAM potential for $\mathrm{Li}$}

In the case of Lithium, we decided to use the approach of D. Belashchenko ${ }^{10}$. His description was appropriately implemented in LAMMPS format by homemade codes. Note that in our calculations, we found that the potential parameters are valid for calculating basic properties of lithium such as lattice constant, cohesive energy, density and heat capacity, when the cutoff distance is taken to be larger than $1.5 a_{0}$ [thirdnearest neighbor $(\mathrm{NN})]$.

\section{III.C Computational details}

Samples for $\mathrm{Pb}$ and $\mathrm{Li}$ ranged in size from 10.000 up to 100.000 atoms. They were canonically generated, energy minimized and equilibrated. We have also tested possible size effects in our results and set up. For example, a $\mathrm{Pb}$ a sample of 5.000 atoms was checked to be equivalent to an equivalent one 10 times bigger in size. Periodic boundary conditions (PBC) were imposed to minimize surface and edge effects.

MD simulations were carried out using the parallel code LAMMPS ${ }^{9}$. Integration algorithms of Verlet and RESPA were benchmarked. The integration time step used for the heating and equilibrating phases was $10^{-4} \mathrm{ps}$. In the production phase we used a dt of $10^{-4}-10^{-5}$ ps and we always tested in both cases a proper convergence. Average length of simulation time in production stage (equilibrium) was around 50 ps.

Trajectories in the canonical ensemble (NVT) were generated after $5 \mathrm{ps}$ of heating by coupling our system to a Berendsen thermostat ${ }^{11}$, and ulterior equilibration using a Nosé-Hoover chain ${ }^{12}$.

\section{RESULTS. VALIDATION OF Li AND Pb EAM POTENTIALS}

A solid model interatomic potential for MD simulations (EAM -type in our present case) must be able to provide a good representation of dynamics, thermodynamics and structural properties of the target material under conditions relevant for technology. In addition, in order to develop future cross potentials ${ }^{13}$ ( $\mathrm{PbLi}, \mathrm{Pb}-\mathrm{He}, \mathrm{Li}-\mathrm{T}$, etc) a set of very particular conditions must be fulfilled to give confidence to the base of the methodology using an effective representation in the EAM alloy composition dependent framework developed by A.Caro ${ }^{14}$.

\section{IV.A. Study Of Static Properties}

As a first test, simple but critical, we have calculated the static properties, cohesive energy and lattice parameter, for $\mathrm{Pb}$ and $\mathrm{Li}$ at $0 \mathrm{~K}$. Doing that we obtain the values represented in table II for $\mathrm{Pb}$ and $\mathrm{Li}$ respectively. Our values are in good agreement with the experimental data reported in the works of Brandes, Toloukian, Dewaele, and Xie. ${ }^{15-18}$. Note that the experimental values reviewed from these works, are $\mathrm{E}_{\mathrm{c}}(\mathrm{Pb})=-2.03 ; \mathrm{a}(\mathrm{Pb})=$ 4.9095 and $\mathrm{E}_{\mathrm{c}}(\mathrm{Li})=-1.63 ; \mathrm{a}(\mathrm{Li})=3.355$.

TABLE II

Cohesive energy, $\mathrm{E}_{\mathrm{c}}$, (in eV/at), and lattice parameter, $\mathrm{a}_{0}$, (in $\AA$ ) for $\mathrm{Pb}$ and $\mathrm{Li}$ calculated using EAM potentials.

\begin{tabular}{|c|c|c|c|c|}
\hline & \multicolumn{2}{|c|}{ fcc } & \multicolumn{2}{c|}{ bcc } \\
\hline Element & $\mathrm{E}_{\mathrm{c}}$ & $\mathrm{a}_{\mathrm{o}}$ & $\mathrm{E}_{\mathrm{c}}$ & $\mathrm{a}_{\mathrm{o}}$ \\
\hline $\mathrm{Pb}$ & -2.014 & 4.894 & -1.97 & 3.78 \\
\hline $\mathrm{Li}$ & -1.675 & 4.21 & -1.705 & 3.3648 \\
\hline
\end{tabular}

Our agreement is not surprising, since the cohesive energy is one of the physical properties used to adjust the parameters that define the potential, in particular the atomic electron-density. The cohesive energy is a measure of the cohesion of the atoms and should be therefore comparable to the sublimation energy.

\section{IV.B. Study Of Structural Properties}

Structural order and distribution of particles within a fluid is frequently well described by the pair-correlation function $\mathrm{g}(\mathrm{r})$. This quantity is related to the probability of finding the center of a particle a given distance from the center of another particle. For short distances, this is related to how the particles are packed together. Therefore, it is a good magnitude to study if we want to be confident in our potential behavior.

It is defined as

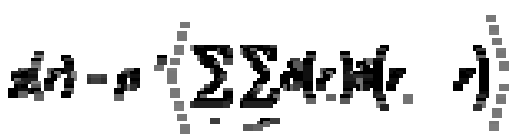

$$
\begin{aligned}
& -v\left(\sum \sum x-x\right)
\end{aligned}
$$

Our calculations using the previous mentioned versions of $\mathrm{EAM}$ potentials for $\mathrm{Li}$ and $\mathrm{Pb}$, are in very good agreement with experimental results. As can be seen in Figure 3, the radial distribution function $(\mathrm{g}(\mathrm{r}))$ matches very well the experimental results reported by Y.Waseda ${ }^{19}$ in the liquid phase for both elements.

The graphs present a comparison of the radial distribution function of both $\mathrm{Pb}$ and $\mathrm{Li}$ at different 
working temperatures of interest in Nuclear Technology. Results on $\mathrm{g}(\mathrm{r})$ are calculated from our MD trajectories and showed in comparison to the experimental results of Waseda.
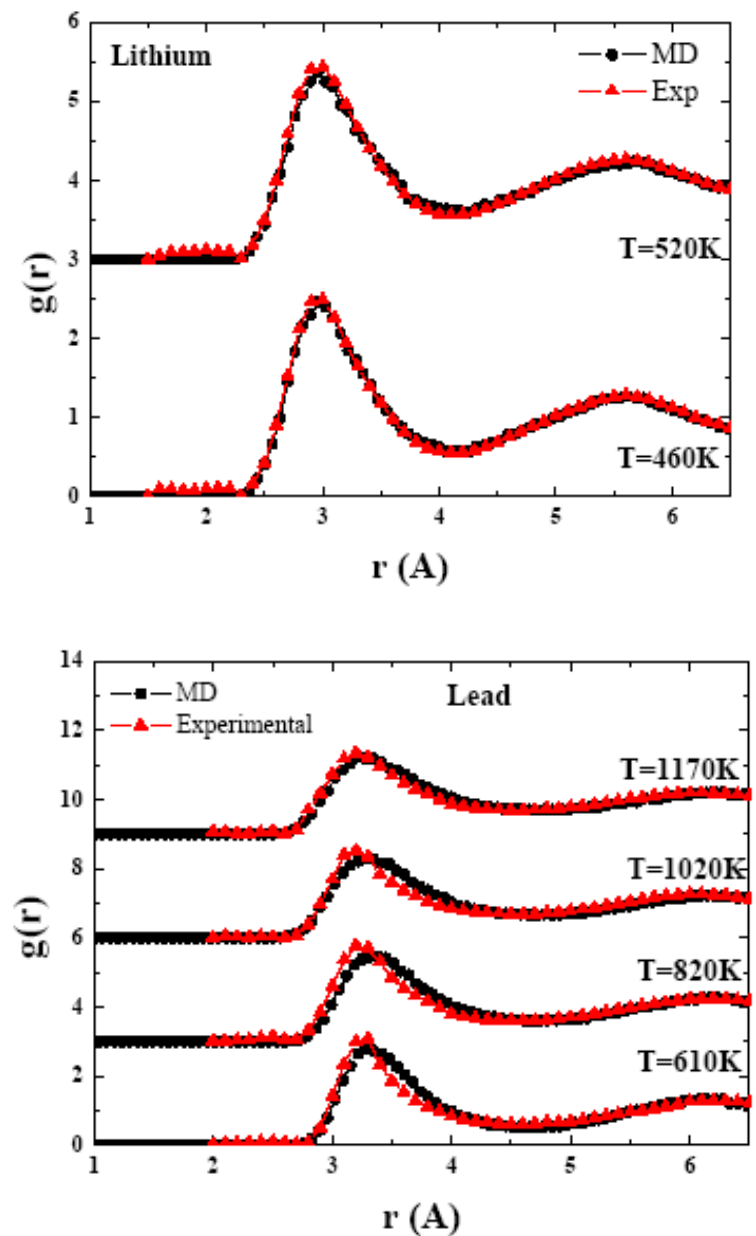

Fig. 3. (Top) Lithium g(r) calculated (circles) compared with experimental results (triangles) at $\mathrm{T}=460$ and $520 \mathrm{~K}$. (Bottom) Lead g(r) calculated (circles) compared with experimental results (triangles) temperature ranging from $\mathrm{T}=610 \mathrm{~K}$ to $\mathrm{T}=1170 \mathrm{~K}$. In both cases a perfect agreement MD simulation - experiment in the radial distribution of the liquid phase is obtained.
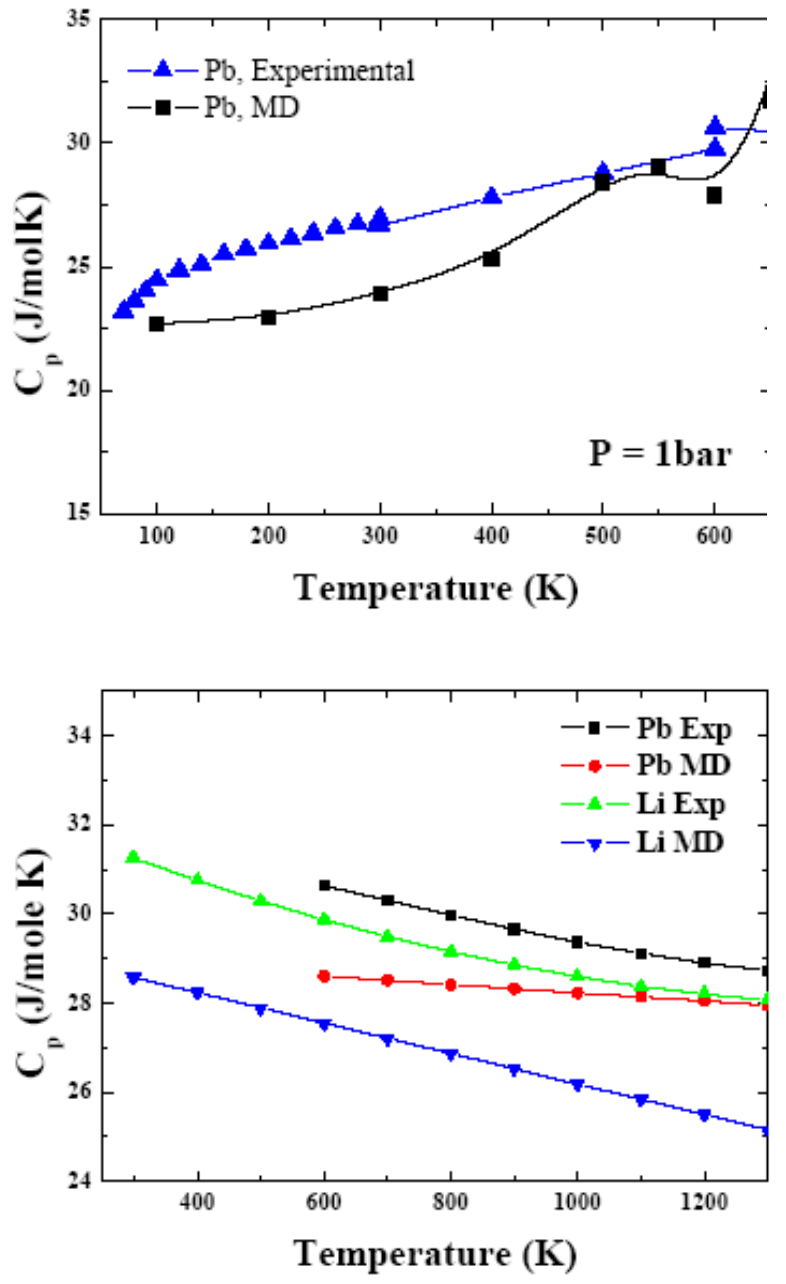

Fig. 5. (top) Heat capacity, $\mathrm{C}_{\mathrm{p}}$, in $\mathrm{J} /$ mole-K, for solid $\mathrm{Pb}$ from MD simulations (squares) and experimental values (triangles) calculated in a MD run. The jump at $600 \mathrm{~K}$ matches with the solid-liquid phase transition. (bottom). Heat capacity, $\mathrm{C}_{\mathrm{p}}$, in $\mathrm{J} / \mathrm{mole}-\mathrm{K}$, for liquid lead and lithium from MD simulations (squares and triangles) compared with experimental values (circles and inverted triangles).

\section{IV.C. Study Of Thermodynamical Properties}

Thermodynamic properties of liquid metals are the base of their industrial applications.

Heat capacity at constant volume, $\mathrm{C}_{\mathrm{v}}$, can be calculated once the system is in equilibrium from energy fluctuations as:

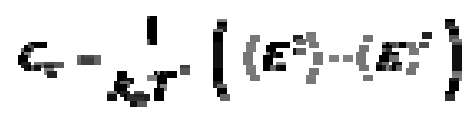

But experimental heat capacity values are usually measured at constant pressure, $\mathrm{C}_{\mathrm{p}}$. These two quantities 
are related by the well know relation $\mathrm{C}_{\mathrm{p}}-\mathrm{C}_{\mathrm{v}}=\mathrm{VT} \alpha^{2} / \beta_{\mathrm{T}}$ where $\alpha$ is the coefficient of thermal expansion and $\beta_{T}$ is the isothermal compressibility. If we calculate the enthalpy of the system, defined as $\mathrm{H}=\mathrm{U}+\mathrm{pV}$ where $U$ is the internal energy of the system, $p$ is the pressure at the boundary of the system and its environment, and $V$ is the volume of the system, then we can easily calculate $C_{p}$.

$$
C_{p}=\left(\frac{\partial H}{\partial T}\right)_{p}
$$

Calculated heat capacity, $\mathrm{C}_{\mathrm{p}}$, gives good agreement with the expected values reported by Gurvich ${ }^{20}$ and Ohse 21.

Moreover, we can also calculate volume and enthalpy change at melting, $\Delta \mathrm{V}$ and $\Delta \mathrm{H}$ respectively, and compare with the proper experimental values ${ }^{21-22}$.

In the case of lead, values agree fairly well with the experiment. Volume change in our simulations is about a $3.8 \%$ while experimentally is expected about $3.6 \%$. In addition, the change in enthalpy (heating) is $5.5 \mathrm{~kJ} / \mathrm{mole}$ while the experimental value is $4,8 \mathrm{~kJ} / \mathrm{mole}$. The result depends on the way we arrive to the final state, i.e, heating or cooling. Cooling the sample from a higher temperature down to the final one the values are: $\Delta \mathrm{H}=5.4$ $\mathrm{kJ} /$ mole and $\Delta \mathrm{V}=2.5 \%$.

For lithium, results depend more on the simulation size. Volume change in our simulations is about a $10.0 \%$ while the experimental one is $1.6 \%$. The change in enthalpy is (heating) $4.5 \mathrm{~kJ} / \mathrm{mole}$ while the experimental value is 3,0 $\mathrm{kJ} /$ mole. In cooling mode, the results are: $\Delta \mathrm{H}=4.5$ $\mathrm{kJ} / \mathrm{mole}$ and $\Delta \mathrm{V}=6.5 \%$.

\section{CONCLUSIONS}

Classical Molecular Dynamics simulations via EAM potentials have showed to be a powerful tool to simulate and understand liquid metals and alloys, in our particular case, lead and lithium. Our results prove the validity of these potentials and provide useful structural and thermodynamical data in conditions of interest to Nuclear Fusion technology. Reported figures are in agreement with experimental results available in the literature. In addition, our work represents a base methodology for the extrapolation of liquid $\mathrm{Pb}$ and $\mathrm{Li}$ properties into regions of temperature and composition where direct experimental measurements either do not exist, or are not accessible.

Moreover, we have tested that our particular choice constitutes a solid base for the development of a future cross $\mathrm{PbLi}$ potential.

\section{ACKNOWLEDGMENTS}

We are grateful to Professor D. Belaschenko for providing us with his lithium EAM potential and fruitful comments. We thank for computing resources in CESGA, Computer Centre of the Institute for Molecular Science. This work was funded by the Spanish National Project on Breeding Blanket Technologies TECNO_FUS through CONSOLIDER_INGENIO 2010 Programme.

\section{REFERENCES}

1. MAS DE LES VALL E. Lead-lithium eutectic material database for nuclear fusion technology. Journal of Nuclear Materials 376 (2008) 353-357.

2. NORAJITRA P. The EU advanced dual coolant blanket concept, Fusion Eng. Des. 61-62 (2002) 449-453.

3. WONG C. P. C. An overview of dual coolant $\mathrm{Pb}-$ $17 \mathrm{Li}$ breeder first wall and blanket concept development for the US ITER-TBM design. Fusion Engineering and Design 81 (2006) 461-467.

4. RICAPITO I. Liquid Meatal Blankets for Fusion Reactors, Fusion Summer School, 10 Sept (2010)

5. BASKES M. I. (1988), MRS Bulletin, 13, 28

6. FOILES S. M. Embedded-atom-method functions for the fcc metals $\mathrm{Cu}, \mathrm{Ag}, \mathrm{Au}, \mathrm{Ni}, \mathrm{Pd}, \mathrm{Pt}$, and their alloys. Phys. Rev. B 33, 7983 (1986).

7. MERKLE K.L. MRS Bulletin, 15, 42 (1990).

8. ZHOU X. W. Atomic scale structure of sputtered metal multylayers. Acta Mater. 49, 4005 (2001).

9. PLIMPTON S. Fast Parallel Algorithms for ShortRange Molecular Dynamics, J Comp Phys, 117, 1-19 (1995).

10. BELASHCHENKO D. Application of the Embedded Atom Model to Liquid Metals: Liquid Lithium High Temperature vol 47 No 2 211-218.

11. BERENDSEN H. J. C. et al . "Molecular-Dynamics with Coupling to an External Bath". Journal of Chemical Physics 81 (8): 3684-3690 (1984).

12. MARTYNA C. J., M. L. Klein, and M. Tuckerman, "Nosé- Hoover Chains - the Canonical Ensemble via Continuous Dynamics", Journal of Chemical Physics 97, 2635-2643 (1992).

13. FRAILE A, CUESTA-LOPEZ S, CARO. A, PERLADO J. M. Under publication process.

14. CARO A. Classical Many-Body Potential for Concentrated Alloys and the Inversion of Order in Iron-Chromium Alloys. PRL 95, 075702 (2005).

15. BRANDES E. A. (Ed.), Smithshells Metals Reference Book, 6th ed., Butterworths, London (1983).

16. TOLOUKIAN Y. S. Thermophysical Properties of Matter, Vol. 1, IFI /Plenum, New York, (1970). 
17. DEWAELE A. Melting of lead under high pressure studied using second-scale time-resolved x-ray diffraction. Phys. Rev. B 76, 144106 (2007).

18. XIE Y. Origin of bcc to fcc phase transition under pressure in alkali metals. New Journal of Physics 10 (2008) 063022 (16pp).

19. WASEDA Y. The Structure of Non-Crystalline Materials: Liquids and Amorphous Solids (McGrawHill, New York, 1980).

20. GURVICH L. V. (1991), Thermodynamic Properties of Individual Substances Fourth Edition, Volume 2 Parts 1 and 2, Hemisphere Pub. Corp. N.Y. (1991).

21. OHSE R. W. (Ed.) Handbook of Thermodynamic and Transport Properties of Alkali Metals, Intern. Union of Pure and Applied Chemistry Chemical Data Series No. 30. Oxford: Blackwell Scientific Publ., 1985, pp. 987.

22. CELINO M. Atomistic simulation of liquid lead and lead-bismuth eutectic. Journal of Nuclear Materials 301 64-69 (2002). 